\title{
Incidence and outcomes of right-sided endocarditis in patients with congenital heart disease after surgical or transcatheter pulmonary valve implantation
}

Sophie Malekzadeh-Milani, MD, Magalie Ladouceur, MD, Laurence Iserin, MD, Damien Bonnet, $\mathrm{MD}, \mathrm{PhD}$, and Younes Boudjemline, $\mathrm{MD}, \mathrm{PhD}$

Objectives: To evaluate right-sided endocarditis and compare the incidence, clinical presentations, and outcomes in patients with a surgical and percutaneous pulmonary valve.

Methods: All patients with infective endocarditis occurring between January 2009 and June 2013 were identified and studied. All consecutive patients who received a pulmonary valve surgically or by percutaneous pulmonary valve implantation (PPVI) during the same period were also evaluated for endocarditis.

Results: During the study period, 31 patients were identified with right-sided endocarditis: 13 had valves implanted during the study period and 18 before. The person-time incidence rates of endocarditis were 1.2 and 3.9 cases $/ 100$ person-years in the surgical and PPVI groups, respectively $(P=.03)$. Clinical presentations, microbiology, and outcomes were comparable in both groups. The implantation-endocarditis time interval was much shorter in the patients in the PPVI group $(P=.0065)$. A past history of endocarditis was found to correlate with endocarditis $(P=.004)$. Infective endocarditis was more frequent in patients with bovine jugular vein valves compared with others $(7.1 \%$ vs $0.84 \%, P=.0117$; odds ratio, 9$)$. Probability of survival at 12,24 , and 36 months was $99.5 \%, 93.8 \%, 93.8 \%$ in the surgical group and $98.9 \%, 96.8 \%, 92.3 \%$ in the PPVI group, respectively $(P=.6)$. Event-free probability including endocarditis was comparable $(P=.1)$.

Conclusions: There is a higher incidence of endocarditis in patients with PPVI compared with surgical pulmonary valves. Clinical and biological features were comparable in both groups. The role of bovine jugular veins in the development of endocarditis is concerning. However, despite a higher incidence of endocarditis in the PPVI group, the probabilities of survival and event-free survival were similar to the surgical group. (J Thorac Cardiovasc Surg 2014;148:2253-9)

See related commentary on pages $2259-60$.

Infective endocarditis (IE) is a life-threatening medical condition that requires immediate attention. Despite significant improvements in the diagnosis and management of IE, mortality remains high. In the congenital heart disease (CHD) population, IE is a concern in patients with prosthetic valves. The diagnosis is usually challenging and delayed, the need for surgery is more frequent, and the prognosis is worse compared with IE in patients with a native valve. ${ }^{1-3}$ About half of the patients with CHD-associated IE develop

From the Centre de Référence Malformations Cardiaques Congénitales ComplexesM3C, Necker Hospital for Sick Children, Assistance Publique des Hopitaux de Paris, Pediatric Cardiology, Paris, France.

Disclosures: Younes Boudjemline is a proctor for Medtronic. All other authors have nothing to disclose with regard to commercial support.

Received for publication April 16, 2014; revisions received July 24, 2014; accepted for publication July 25, 2014; available ahead of print Sept 11, 2014.

Address for reprints: Younes Boudjemline, MD, PhD, Hôpital Necker Enfants Malades, Cardiologie Pédiatrique, 149 rue de Sèvres, 75015 Paris Cedex, France

(E-mail: younes.boudjemline@nck.aphp.fr).

0022-5223/\$36.00

Copyright (c) 2014 by The American Association for Thoracic Surgery

http://dx.doi.org/10.1016/j.jtcvs.2014.07.097 major complications. Overall mortality of CHD-associated IE decreased to $10 \%$ in 1990 in comparison with $30 \%$ in adults with IE and structural heart disease. ${ }^{4,5}$ Mortality from surgery for IE is up to $15 \%$; mortality after 1 year I $40 \%$ to $50 \%{ }^{5,6}$

There is a paucity of data on the incidence, clinical presentation, treatment, and outcomes of selective right-sided endocarditis in patients with $\mathrm{CHD}$ with surgical or transcatheter pulmonary valve implantation. ${ }^{7-10}$ Percutaneous pulmonary valve implantation (PPVI) is now recognized as the treatment of choice for dysfunctional right ventricular outflow tracts (RVOT). ${ }^{11}$ After more than a decade, its usefulness has been recognized; it offers a good alternative to surgery for patients with hemodynamically significant RVOT diseases. ${ }^{12}$ However, there are increasing reports of endocarditis with the most frequently used valve stent (ie, the Melody valve [Medtronic, Minneapolis, Minn]). ${ }^{13-16}$ To date, there are no data comparing surgical and transcatheter endocarditis. We reviewed all cases of right-sided endocarditis in patients who underwent surgical and transcatheter treatment at our center during the same period to study the demographics, clinical presentation, microbiology, treatment, and outcomes. 


\section{Abbreviations and Acronyms \\ $\mathrm{CHD}=$ congenital heart disease \\ $\mathrm{CI}=$ confidence interval \\ IE $=$ infective endocarditis \\ PPVI = percutaneous pulmonary valve implantation \\ PVR = pulmonary valve replacement \\ $\mathrm{RVOT}=$ right ventricular outflow tract}

\section{MATERIALS AND METHODS}

Data were collected from our institutional review board-approved database. All patients with IE occurring between January 2009 and June 2013 were identified and studied. Diagnosis was made using the modified Duke criteria (Table 1). All patients who received a pulmonary valve surgically (PVR) or percutaneously during the study period at our institution were also identified and included in the study.

Data were collected retrospectively for the surgical group and prospectively for the transcatheter patients (this population was part of a large prospective clinical trial). Patients receiving a valve in any other position either percutaneously or surgically were excluded from the study. Patients followed up abroad were also excluded from the study.

A detailed review of the medical history of all patients was undertaken, including demographic characteristics, number of surgeries, number of cardiac catheterizations, type of conduit, history of endocarditis and comorbidities (any associated chronic medical condition, syndrome, genetic abnormalities, chronic infection). All had a detailed echocardiogram before, during, and after implantation. Follow-up outcomes were recorded. Patients were diagnosed as having IE based on the modified Duke criteria. Clinical presentation, bacteriologic diagnosis, evolution, and treatment were recorded.

Prevention of endocarditis in the PPVI group evolved over time. When we started the PPVI program, the patients were free of infection at the time of implantation and received antibioprophylaxis at the time of the procedure. Since mid-2011, the same protocol has been used for all patients receiving a valve, either surgically or percutaneously. Before the valve procedure, all patients undergo dental clearance. Cefamandole is given in the operating room or in the catheterization laboratory at the start of the procedure and is continued for 24 hours.

\section{Statistical Analysis}

Analyses were performed using MedCalc software (Mariakerke, Belgium). A comparison between the surgical and transcatheter PPVI groups was performed for endocarditis. Endocarditis occurring on conduits placed before the study began were excluded from the calculation of the incidence of IE.

The person-time incidence rate with the $95 \%$ confidence interval (CI) for a Poisson distribution was calculated for the PPVI group and the surgical group. The probability of survival and the probability of cardiovascular event/endocarditis-free survival were calculated for each group using the Kaplan-Meyer method. Survival probability included death and heart transplantation; cardiovascular events included IE, surgery for IE, or death. Data are presented as the mean value \pm SD when variables were normally distributed, and the median value with $95 \%$ CI when it was not. The PPVI and surgical groups were compared using the Wilcoxon test for quantitative variables and the $\chi^{2}$ test or Fisher test for qualitative variables. The relationship between risk factors for IE (sex, age, type of CHD, age at PVR, pulmonary arterial stenting and the number of procedures, history of infectious history, history of IE and comorbidities, type of prosthetic material for pulmonary valve) and IE was assessed using Cox proportional hazard regression analysis. Only factors significantly associated with IE with $P<.05$ where used in the multivariate model.

\section{RESULTS \\ Endocarditis Occurring Between January 2009 and June 2013}

During the study period, 31 patients were identified with right-sided endocarditis: 13 had valves implanted during the study period and 18 had right ventricle to pulmonary artery conduits implanted before 2009. Twenty-three patients had a surgical conduit and 8 patients had Melody valve implantation (Table 2). In the surgical group, 3 had homografts, 3 had a nonvalve conduit, and 17 had a bioprosthesis (14 Contegra [Medtronic], 1 Hemashield [St Jude Medical, St Paul, Minn], 1 Magma [Edward Lifesciences, Irvine, Calif], and 1 Hancock [Medtronic]).

When we compared surgical IE and PPVI IE, gender and the number of previous surgeries were similar (Table 2). The implantation-IE time interval was different in the 2 groups; IE occurred much earlier in the PPVI group compared with the surgical group $(P=.0065)$. Only 5 of 23 occurrences of IE during the study period had RVOT conduits implanted during the study period; all others had RVOT conduits implanted before January 2009. In addition, early onset of IE (defined as endocarditis within 1 year of implantation) was more frequent in the PPVI group and this tended to reach statistical significance $(P=.052)$.

The severity of the clinical presentation at diagnosis was not different in the 2 groups. In the surgical group, severe presentation was always associated with Staphylococcus aureus infection. Gradients across the RVOT increased globally in both groups during IE and were similar before and during IE. In the surgical group, vegetation was seen in the RVOT in 18 patients. In the PPVI group with IE, vegetation was identified in the RVOT in 6 of 8 cases. The size of the vegetation was not reported but the increase in the RVOT gradient in most of these patients in both groups indicates that the vegetation was significant. The need for surgery to remove the infected material was not different in for surgical and transcatheter IE (Table 2). The microbiological diagnosis for IE was also similar in both groups (Table 3 ).

Overall mortality (related or unrelated to IE) at last follow-up was 19\%: $37 \%$ in the PPVI group and $13 \%$ in the surgical group $(P=\mathrm{NS})$. In the surgical group with IE $(\mathrm{n}=23), 2$ patients had surgery to remove the infected conduit, 2 were treated medically (1 died 5.5 months after the onset of IE of febrile shock) and 1 had early heart transplantation for intractable endocarditis. In the PPVI group with IE $(n=8), 2$ died acutely of severe cardiogenic shock; another had balloon dilation of the RVOT and died 6 months after onset of IE. Death was caused by biventricular heart failure and not IE. One patient needed emergency balloon dilation of the RVOT followed by surgery, 1 patient needed surgery, and 3 patients were treated medically. 
TABLE 1. Modified Duke criteria

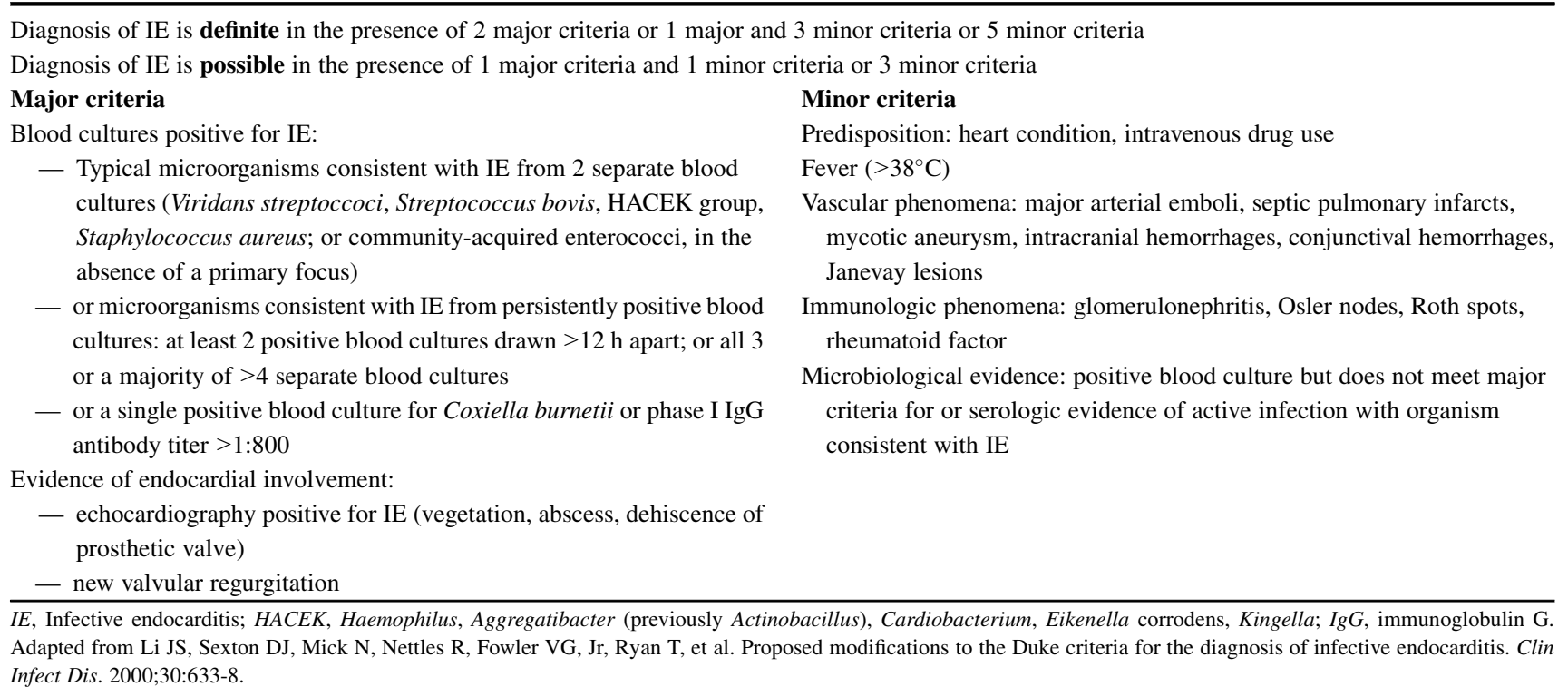

\section{Incidence of IE in the Surgical and PPVI Groups}

Between January 2009 and June 2013, 93 patients received 93 Melody valves and 195 right ventricle to pulmonary artery conduits were implanted in 190 patients in our institution. Demographics, types of conduit, and reasons for implantation are summarized in Table 4. The period of follow-up was similar for the surgical and PPVI groups with a median of 24.1 months (95\% CI, 19.9-29.9 months) and 23.8 months (95\% CI, 17.5-32.5 months), respectively. Patients in the surgical group were younger than patients receiving a Melody valve (median, 13.3 years vs 20.1 years, $P<.01)$. Patients undergoing Melody valve implantation had a higher number of previous surgeries than the surgical patients $(P<.001)$. Amongst the 288 RVOT interventions, 13 patients developed right-sided endocarditis: 5 of 190 surgical patients (incidence, $2.6 \% \pm 2.2 \%$; $95 \% \mathrm{CI}, 0.35 \%$ $4.8 \%$ ) and 8 of 93 PPVI patients (incidence, $8.6 \% \pm$ $5.7 \%$; $95 \%$ CI, $2.9 \%-14.3 \%$ ). Person-time incidence rates of IE were 2.4, 1.2, and 3.9 cases per 100 person-years for the total population, the surgical group, and the PPVI group, respectively (surgical vs PPVI, $P=.03$ ). The probability of being free of IE in the PPVI group was significantly lower compared with the surgical group $(P=.029$; Figure 1$)$.

\section{Risk Factors}

In the surgical group, 3 of 5 patients had a previous history of IE. In the PPVI group, 1 patient had a previous history of IE. These patients had different causative germs except for 1 patient in the surgical group who had early recurrence of IE with Staphylococcus aureus (Table 5). Using univariate analysis, IE was 7 times more likely to occur when the patient had a history of IE in the surgical group (relative risk, 7.3; 95\% CI, 2.2-23.6; $P=.001$ ) and 3 times more likely in the PPVI group (relative risk, 3.31; 95\% CI, $1.1-10.1 ; P=.03)$. There was no association between the occurrence of IE and age at time of the procedure, gender, history of noncardiac bacterial infection, presence of comorbidities, number of surgeries, and the presence of stents in the pulmonary arteries. In multivariate analysis, only a history of IE was associated with IE $(P=.004)$. When we compared the person-years incidence rate of IE with and without a history of IE, the difference was significant in the surgical group $(19.7 \%$ with history of IE and $0.5 \%$ without a history of IE, $P<.0001)$ but not in the PPVI group $(P=.7)$. Moreover, when analyzing the type of valves regardless of the implantation technique, IE was more frequent in patients with bovine jugular vein valves (ie, Contegra and Melody) compared with others $(12 / 169=7.1 \%[4 \%-12 \%]$ vs $1 / 119=0.84 \%$ $[0 \%-5 \%], P=.0117 ;$ OR $=9[1.16-70.33])$.

\section{Outcome in Patients Who Had Surgical and PPVI Procedures}

In this series of patients, 11 surgical patients died as a result of cardiac events including 2 in the context of IE. Four PPVI patients died: 3 patients described earlier and 1 patient (who did not have IE) with biventricular failure (end-stage ventricular failure). The all-cause mortality rate (including endocarditis) was not different between the 2 groups (surgical group, $5.61 \%$; PPVI group, $4.30 \%$; $P=.6$ ). The probability of survival at 12,24 , and 36 months was $99.5 \%, 93.8 \%$, and $93.8 \%$ in the surgical group and $98.9 \%, 96.8 \%$, and $92.3 \%$ in the PPVI group, respectively $(P=.6$; Figure 2$)$. The probability of cardiovascular eventfree survival including IE was not different between the 2 groups $(P=.1$; Figure 3$)$. 
TABLE 2. Characteristics of the surgical population and the PPVI (Melody valve) population

\begin{tabular}{|c|c|c|c|}
\hline & $\begin{array}{l}\text { Surgery } \\
(\mathbf{N}=195)\end{array}$ & PPVI $(\mathbf{N}=93)$ & $P$ value \\
\hline $\begin{array}{l}\text { Age at PVR, y (median) } \\
{[95 \% \mathrm{CI}]}\end{array}$ & $13.3[11.6-15.0]$ & $20.1[18.2-21.8]$ & $<.01$ \\
\hline Male/female & $111 / 79$ & $52 / 41$ & - \\
\hline Type of defect & & & - \\
\hline TOF & 69 & 24 & \\
\hline PA-VSD & 37 & 23 & \\
\hline Truncus arteriosus & 12 & 11 & \\
\hline Aortic disease & 31 & 13 & \\
\hline DORV-PS & 9 & 3 & \\
\hline Complex & 32 & 19 & \\
\hline $\begin{array}{l}\text { Number of surgeries, mean } \\
\qquad[95 \% \mathrm{CI}]\end{array}$ & $1[1-2]$ & $2[2-3]$ & $<.001$ \\
\hline Type of conduit & & & - \\
\hline Homograft & $65(33 \%)$ & $19(20 \%)$ & \\
\hline Bioprosthesis* & $37(19 \%)$ & $40(43 \%)$ & \\
\hline Contegra & $76(39 \%)$ & $12(13 \%)$ & \\
\hline Nonvalve Gore-Tex $\dagger$ conduit & $17(9 \%)$ & $5(6 \%)$ & \\
\hline Patched RVOT & - & $17(18 \%)$ & \\
\hline History of endocarditis & 11 & 6 & NS \\
\hline Comorbidities & 36 & 22 & NS \\
\hline Outcome & & & - \\
\hline IE & 5 & 8 & \\
\hline Death & 11 & 4 & \\
\hline Heart transplantation & 1 & 0 & \\
\hline \multicolumn{4}{|c|}{$\begin{array}{l}P P V I \text {, Percutaneous pulmonary valve implantation; } P V R \text {, pulmonary valve replace- } \\
\text { ment; } C I \text {, confidence interval; TOF, tetralogy of Fallot; PA-VSD, pulmonary } \\
\text { atresia-ventricular septal defect; DORV-PS, double-outlet right ventricle with pulmo- } \\
\text { nary stenosis; } R V O T \text {, right ventricular outflow tract; } N S \text {, not significant; } I E \text {, infective } \\
\text { endocarditis. *Bioprosthesis: Vascutek (Terumo, Inchinnan, Scotland), Carbomedics } \\
\text { (Sorin, Clamart, France), Freestyle (Medtronic, Minneapolis, Minn), Carpentier- } \\
\text { Edwards (Edwards Lifesciences, Irvine, Calif), Hancock (Medtronic), Perimount } \\
\text { (Edwards Lifesciences), Magna (Edwards Lifesciences), Hemashield (St Jude Med- } \\
\text { ical, St Paul, Minn), Labcor (Labcor Laboratorios, Belo Horizonte, Brazil), Shelhigh } \\
\text { (Shelhigh Inc, Millburn, NJ), St Jude aortic (St Jude Medical). †Gore-Tex; W.L. Gore } \\
\text { and Associates, Flagstaff, Ariz. }\end{array}$} \\
\hline
\end{tabular}

\section{DISCUSSION}

Despite a sizable number of interventions and surgeries on RVOT, there are limited data on the incidence, clinical presentation, treatment, and outcomes of right-sided endocarditis in patients with CHD with prosthetic material implanted at the RVOT. ${ }^{7-16}$ We reviewed all cases of right-sided endocarditis in patients treated at our centre during the study period. Patients were diagnosed with IE based on the modified Duke criteria (Table 1).

Various valves and conduits have been in use during the study period. The incidence of IE based on the pulmonary valve prosthetic material showed significant variation. We did not find a difference in the incidence of IE between conduits but the number of patients was probably too small for statistical analysis. Moreover, Albanesi and colleagues ${ }^{8}$ recently reported the long-term results on the Contegra valve and described an incidence of IE as high as $11.3 \%$.
TABLE 3. Patients with IE: comparison between surgical IE and PPVI (Melody valve) IE

\begin{tabular}{|c|c|c|c|}
\hline & $\begin{array}{l}\text { Surgery } \\
(\mathbf{n}=\mathbf{2 3})\end{array}$ & PPVI $(n=8)$ & $P$ value \\
\hline Age, y (median) $[95 \% \mathrm{CI}]$ & 15.9 [10.5-21.9] & $27.5[13.5-47.9]$ & .06 \\
\hline Male/female & $16 / 7$ & $7 / 1$ & NS \\
\hline \multicolumn{4}{|l|}{ Type of defect, $n$} \\
\hline DORV-PS & 6 & 2 & \\
\hline Truncus arteriosus & 1 & 1 & \\
\hline PA-VSD & 6 & 1 & \\
\hline TOF & 7 & 2 & \\
\hline Aortic stenosis & 2 & 2 & \\
\hline Complex & 1 & - & \\
\hline $\begin{array}{c}\text { Number of surgeries, } \\
\text { mean } \pm \mathrm{SD}\end{array}$ & $2.5 \pm 1.3$ & $2.6 \pm 0.7$ & NS \\
\hline Conduit, $\mathrm{n}$ & & & - \\
\hline HG & 3 & 2 & \\
\hline Contegra & 14 & 0 & \\
\hline Bioprosthesis & 3 & 5 & \\
\hline Nonvalve conduit & 1 & 0 & \\
\hline Patched & 2 & 1 & \\
\hline Comorbidities & 9 & 3 & - \\
\hline History of infection & 7 & 1 & - \\
\hline History of IE & 4 & 1 & - \\
\hline $\begin{array}{l}\text { Age of the conduit or last } \\
\text { surgery, y (mean) } \\
{[95 \% \mathrm{CI}]}\end{array}$ & 9.2 [2.7-11.9] & $11.2[2.3-16.3]$ & NS \\
\hline $\begin{array}{l}\text { Age of Melody valve or the } \\
\text { conduit, y (mean) } \\
{[95 \% \mathrm{CI}]}\end{array}$ & $9.2[2.7-11.9]$ & $0.95[0.29-3.2]$ & .0065 \\
\hline \multicolumn{4}{|l|}{ Last echo gradient } \\
\hline$<2 \mathrm{~m} / \mathrm{s}$ & 5 & 0 & NS \\
\hline $2-4 \mathrm{~m} / \mathrm{s}$ & 14 & 7 & \\
\hline$>4 \mathrm{~m} / \mathrm{s}$ & 4 & 1 & \\
\hline \multicolumn{4}{|l|}{ Clinical presentation } \\
\hline $\begin{array}{l}\text { Severe (sepsis, heart } \\
\text { failure) }\end{array}$ & 4 & 4 & NS \\
\hline Fever, malaise & 19 & 4 & \\
\hline $\begin{array}{l}\text { Early onset after surgery } \\
\text { or after PPVI, n }(\%)\end{array}$ & $3(13.04)$ & $4(50)$ & .05 \\
\hline \multicolumn{4}{|l|}{ Echo gradient during IE } \\
\hline$<2 \mathrm{~m} / \mathrm{s}$ & 2 & 0 & NS \\
\hline $2-4 \mathrm{~m} / \mathrm{s}$ & 11 & 5 & \\
\hline$>4 \mathrm{~m} / \mathrm{s}$ & 10 & 3 & \\
\hline Vegetation, $\mathrm{n}$ & 18 & 6 & - \\
\hline Shock on admission, $\mathrm{n}(\%)$ & $4(17.4)$ & $3(37.5)$ & NS \\
\hline $\begin{array}{l}\text { Need for surgery because } \\
\text { of IE, } \mathrm{n}(\%)\end{array}$ & $13(56.5)$ & $4(50)$ & NS \\
\hline \multicolumn{4}{|l|}{ Outcome } \\
\hline Alive & 20 & 5 & NS \\
\hline Death & $3(1 \mathrm{TLX})$ & 3 & \\
\hline Early death & $2(1 \mathrm{TLX})$ & 2 & \\
\hline Late death & 1 & 1 & \\
\hline
\end{tabular}

$\overline{I E \text {, Infective endocarditis; } P P V I \text {, percutaneous pulmonary valve implantation; } C I}$, confidence interval; NS, not significant; DORV-PS, double-outlet right ventricle with pulmonary stenosis; $P A-V S D$, pulmonary atresia-ventricular septal defect; $T O F$, tetralogy of Fallot; $S D$, standard deviation; $H G$, homograft; $T L X$, heart transplantation. 
TABLE 4. Microorganisms found in endocarditis

\begin{tabular}{lcc}
\hline \multicolumn{1}{c}{ Bacteria } & PPVI $(\mathbf{n}=\mathbf{8})$ & Surgery $(\mathbf{n}=\mathbf{2 3})$ \\
\hline Streptococcus & 4 & 9 \\
Staphylococcus epidermidis & 2 & 4 \\
Methicillin-sensitive & 1 & 3 \\
$\quad$ Staphylococcus aureus & - & 1 \\
Bartonnella & - & 1 \\
Kingella kingae & - & 1 \\
Enterobacter faecium & - & 1 \\
Enterococcus faecalis & - & 2 \\
Pseudomonas aeruginosa & 1 & - \\
Propionibacterium acnes & - & 1 \\
Negative blood culture & - &
\end{tabular}

$P P V I$, Percutaneous pulmonary valve implantation.

The incidence of IE related to PPVI with the Melody valve was within the same range as that for the Contegra. This peculiar finding raises questions on the nature of the prosthetic material and susceptibility to IE; the Contegra and Melody valves have the same biological origin (ie, bovine jugular vein). Following this common origin, we analyzed the risk of endocarditis in all implanted conduits regardless of implantation technique and found a close association between bovine jugular vein and IE. There are as yet no clear explanations for this. Various interesting hypotheses may be postulated, such as higher tropism for bacteria, higher thrombogenicity, biologically active surface working like a sink in contrast to other inert conduits or homografts, lower rate of endothelialization, and so forth.

The findings put bovine jugular vein material as a potentially important substrate for such high susceptibility to endocarditis. However, the relatively high incidence of IE with the Melody and Contegra valves is probably more multifactorial resulting from complex interactions of substrates and triggers: intrinsic susceptibility of the conduit for IE, residual turbulence in the RVOT, unmodifiable anatomic factors, and abrupt cessation of antiaggregrant therapy with thrombi filling up the valve cusps.

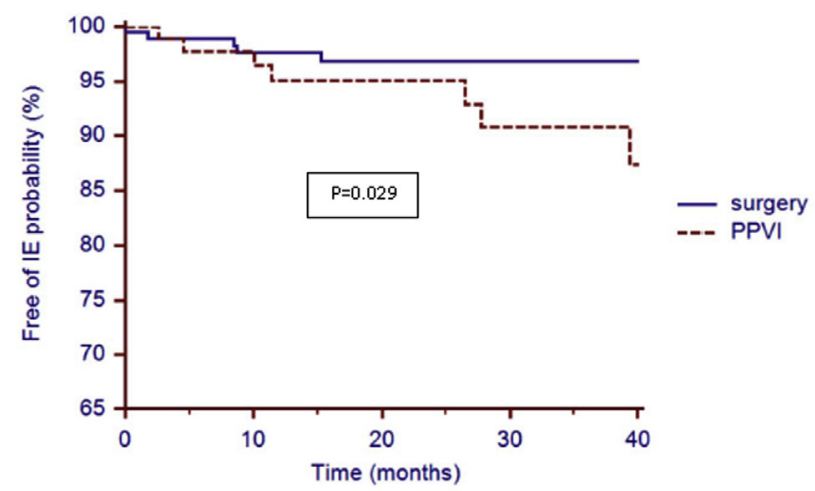

FIGURE 1. Freedom from infective endocarditis in the surgical group and the percutaneous pulmonary valve implantation (Melody valve) group. $I E$, Infective endocarditis; PPVI, percutaneous pulmonary valve implantation.
One of the answers to the potential role of the type of conduit in the development of IE may be elucidated by the ongoing studies of the SAPIEN valve inserted in the pulmonary position. ${ }^{17}$ However, preliminary results on pericardial valves in the aortic position showed an incidence of IE of $3.4 \%$ at 1 year and this is similar to what we describe here. ${ }^{18}$ Long-term studies focusing on right-sided lesions are still awaited before drawing final conclusions.

When comparing surgical RVOT IE and transcatheter RVOT IE, there was no difference in the clinical presentation. The microbiological diagnosis, treatment, and outcomes were similar in both groups, confirming that prosthetic valve IE is a serious complication requiring urgent medical treatment and surgery to remove the infected material in most cases. Global mortality remains high regardless of the type of reconstructed RVOT and despite aggressive treatment. The main difference in the 2 groups was the time between implantation and onset of IE, which was noted to be much earlier after valve implantation in the PPVI group. However, this does not imply that Melody valve IE always has an early presentation because some of the patients presented with IE 4 years after PPVI. On multivariate analysis, a past history of IE was the only risk factor identified. This finding raises the question of whether patients with a past history of IE are good candidates for PPVI. There is no clear answer to that question because the risk was only statistically significant for the surgical population and not for the PPVI patients. We still consider these patients as candidates for PPVI if the patient is free of endocarditis 1 year after previous endocarditis. Larger studies are necessary before giving a conclusive answer.

Despite a higher incidence of endocarditis in the Melody PPVI group compared with surgery, it cannot be concluded that the use of this device may be harmful. The overall results should be put into perspective and the impact of different techniques in the 2 groups may be playing some role. There seems to be some trade off because although patients with PPVI have a higher risk for endocarditis, it is also possible that they may have less invasive, perioperative or other cardiovascular events and complications. In our study, survival curves and freedom from cardiovascular events including IE were similar in the surgical and the PPVI groups despite a higher rate of endocarditis in the PPVI group.

In addition to the different techniques and substrates used, it could be advocated that sterile techniques are more stringent in the operating room than in the catheterization laboratory. This is undoubtedly true but early onset of IE in the PPVI group is not the only mode of presentation and, more importantly, bacteria causing IE are usually issued from the ear, nose, and throat or are methicillin-sensitive Staphylococcus, making procedural contamination less likely to be the cause.

Patients should be made aware of the possible complications. Strict measures should be taken to limit the risk of 
TABLE 5. Microorganisms in patients with a history of infective endocarditis

\begin{tabular}{llll}
\hline Patient number & Group & $\begin{array}{c}\text { Interval between first and } \\
\text { second IE }\end{array}$ & Microorganism at first IE \\
\hline 1 & Surgery & $15 \mathrm{~d}$ & Microorganism at second IE \\
2 & Surgery & $3 \mathrm{mo}$ & Stame bacteria \\
3 & Surgery & $14 \mathrm{mo}$ & Enterococcus \\
4 & Surgery & $4 \mathrm{y}$ & Staphylococcus epidermidis \\
5 & PPVI & $23 \mathrm{mo}$ & Negative blood culture \\
\hline IE, Infective endocarditis; PPVI, percutaneous pulmonary valve implantation. & Streptococcus gordonii
\end{tabular}

$I E$, Infective endocarditis; $P P V I$, percutaneous pulmonary valve implantation.

endocarditis with antibioprophylaxis, strict asepsis, and so forth. ${ }^{19}$ Patients undergoing PPVI should be considered as patients undergoing surgery and should have the same preliminary testing (dental care, otorhinolaryngology, and so forth). Physicians should be aware of this complication and should refer the patient to a tertiary hospital with any suspicion of endocarditis for prompt diagnosis and management. Our management strategy after the onset of IE was based on the European Society for Cardiology guidelines, ${ }^{5}$ Antimicrobial therapy was given for 6 weeks. Indications for surgery were heart failure (secondary to increased right ventricular outflow tract obstruction), uncontrolled sepsis with septic shock, or persistent infection in the urgent cases. In semielective or elective surgery for IE, the reason for intervention was right ventricular outflow tract obstruction or relapse of IE despite adequate antibiotic treatment.

\section{Limitations}

Given the retrospective nature of the data collection in the surgical group, it is possible that anecdotal episodes of IE may not have been reported in our database. The incidence of IE may thus have been underestimated in the surgical group. However, to reduce this bias, each patient and the doctors following the patients were contacted by phone. Patients from abroad were excluded from this study. All patients in the Melody valve group were followed strictly according to protocol in our institution with accurate

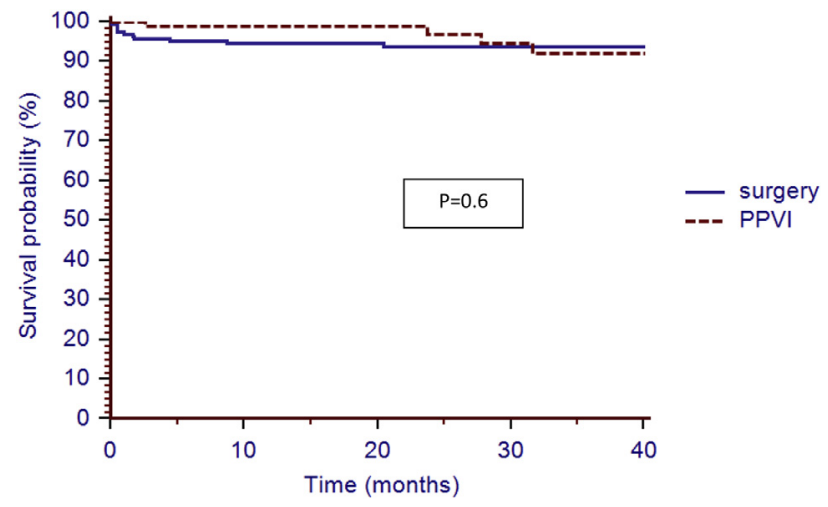

FIGURE 2. Survival curve in the surgical group and the percutaneous pulmonary valve implantation (Melody valve) group. PPVI, Percutaneous pulmonary valve implantation. diagnosis and reporting of IE. This is a descriptive study and the number of events is low making the statistics less robust. We were unable to accurately determine the incidence of IE based on the bioprosthetic conduit material in more detail because multiple conduits were used over the years. Thus, the global incidence was assessed.

\section{CONCLUSIONS}

RVOT IE in patients with CHD is a serious complication requiring aggressive medical and surgical treatment in most cases. There is a high person-time incidence of endocarditis in patients with the Melody valve compared with surgically implanted pulmonary valves. This is probably multifactorial. Intrinsic characteristics of the bovine jugular vein may play a major role in IE as we found an increased risk of endocarditis in patients receiving a bovine jugular vein valve either surgically or by the transcatheter technique. It is possible that there is enhanced tropism of microbes to the bovine jugular vein, however, in vitro studies may be required to establish this hypothesis. Clinical presentation and a microbiological diagnosis of IE were comparable in the surgical and PPVI patients. A past history of IE remains a major risk factor for the development of future IE in both groups. Multicenter studies are needed to pool a larger number of patients and identify strong predictors for IE in this population.

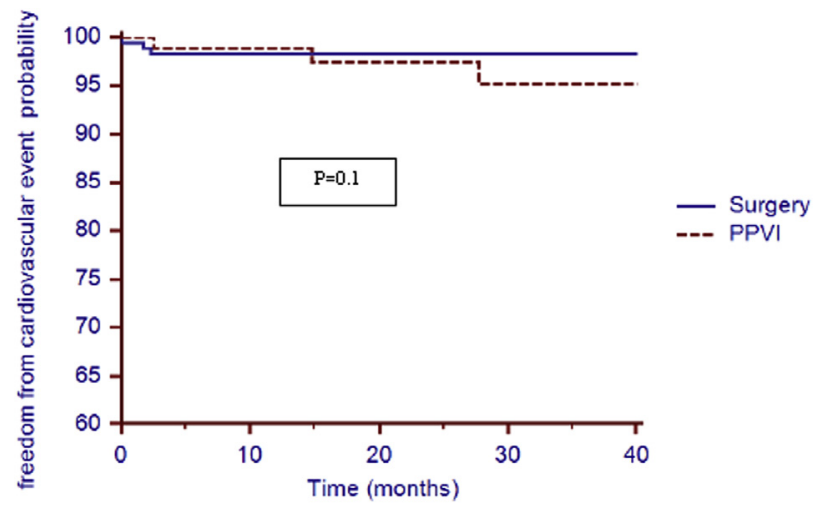

FIGURE 3. Freedom from cardiovascular events in the surgical group and the percutaneous pulmonary valve implantation (Melody valve) group. $P P V I$, Percutaneous pulmonary valve implantation. 
Additional input from studies on other transcatheter heart valves may answer questions on whether the percutaneous approach is a possible risk factor along with other substrates based on prosthetic material. Despite a higher incidence of endocarditis with the Melody valve, probabilities of survival and event-free survival were similar to the surgical group.

The authors thank Dr Mehul Patel for editing the paper.

\section{References}

1. Fortún J, Centella T, Martín-Dávila P, Lamas MJ, Pérez-Caballero C, FernándezPineda L, et al. Infective endocarditis in congenital heart disease: a frequent community-acquired complication. Infection. 2013;41:167-74.

2. Knirsch W, Nadal D. Infective endocarditis in congenital heart disease. Eur J Pediatr. 2011;170:1111-27.

3. Rushani D, Kaufman JS, Ionescu-Ittu R, Mackie AS, Pilote L, Therrien J, et al. Infective endocarditis in children with congenital heart disease: cumulative incidence and predictors. Circulation. 2013;128:1412-9.

4. Mulder BJ. Endocarditis in congenital heart disease: who is at highest risk? Circulation. 2013;128:1396-7.

5. Habib G, Hoen B, Tornos P, Thuny F, Prendergast B, Vilacosta I, et al; ESC Committee for Practice Guidelines. Guidelines on the prevention, diagnosis, and treatment of infective endocarditis (new version 2009): the Task Force on the Prevention, Diagnosis, and Treatment of Infective Endocarditis of the European Society of Cardiology (ESC). Endorsed by the European Society of Clinical Microbiology and Infectious Diseases (ESCMID) and the International Society of Chemotherapy (ISC) for Infection and Cancer. Eur Heart J. 2009;30:2369-413.

6. Murdoch DR, Corey GR, Hoen B, Miró JM, Fowler VG Jr, Bayer AS, et al; International Collaboration on Endocarditis-Prospective Cohort Study (ICE-PCS) Investigators. Clinical presentation, etiology, and outcome of infective endocarditis in the 21st century: the International Collaboration on EndocarditisProspective Cohort Study. Arch Intern Med. 2009;169:463-73.

7. Niwa K, Nakazawa M, Tateno S, Yoshinaga M, Terai M. Infective endocarditis in congenital heart disease: Japanese national collaboration study. Heart. 2005;91: 795-800.
8. Albanesi F, Sekarski N, Lambrou D, Von Segesser LK, Berdajs DA. Incidence and risk factors for Contegra graft infection following right ventricular outflow tract reconstruction: long-term results. Eur J Cardiothorac Surg. 2014;45 1070-4.

9. Meyns B, Jashari R, Gewillig M, Mertens L, Komárek A, Lesaffre E, et al. Factors influencing the survival of cryopreserved homografts. The second homograft performs as well as the first. Eur J Cardiothorac Surg. 2005;28:211-6.

10. Breymann T, Blanz U, Wojtalik MA, Daenen W, Hetzer R, Sarris G, et al. European Contegra multicentre study: 7-year results after 165 valved bovine jugular vein graft implantations. Thorac Cardiovasc Surg. 2009;57:257-69.

11. Bonhoeffer P, Boudjemline Y, Saliba Z, Merckx J, Aggoun Y, Bonnet D, et al Percutaneous replacement of pulmonary valve in a right-ventricle to pulmonary-artery prosthetic conduit with valve dysfunction. Lancet. 2000;356: 1403-5.

12. Eicken A, Ewert P, Hager A, Peters B, Fratz S, Kuehne T, et al. Percutaneous pul monary valve implantation: two-centre experience with more than 100 patients. Eur Heart J. 2011;32:1260-5.

13. Patel M, Iserin L, Bonnet D, Boudjemline Y. Atypical malignant late infective endocarditis of Melody valve. J Thorac Cardiovasc Surg. 2012;143:e32-5.

14. Atamanyuk I, Raja SG, Kostolny M. Bartonella henselae endocarditis of percutaneously implanted pulmonary valve. J Heart Valve Dis. 2012;21:682-5.

15. Gillespie MJ, Rome JJ, Levi DS, Williams RJ, Rhodes JF, Cheatham JP, et al Melody valve implant within failed bioprosthetic valves in the pulmonary position: a multicenter experience. Circ Cardiovasc Interv. 2012;5:862-70.

16. Buber J, Bergersen L, Lock JE, Gauvreau K, Esch JJ, Landzberg MJ, et al. Bloodstream infections occurring in patients with percutaneously implanted bioprosthetic pulmonary valve: a single-center experience. Circ Cardiovasc Interv. 2013;6:301-10.

17. Haas NA, Moysich A, Neudorf U, Mortezaeian H, Abdel-Wahab M Schneider H, et al. Percutaneous implantation of the Edwards SAPIEN(TM) pulmonic valve: initial results in the first 22 patients. Clin Res Cardiol. 2013;102: 119-28.

18. Puls M, Eiffert H, Hünlich M, Schöndube F, Hasenfuß G, Seipelt R, et al Prosthetic valve endocarditis after transcatheter aortic valve implantation: the incidence in a single-centre cohort and reflections on clinical, echocardiographic and prognostic features. EuroIntervention. 2013;8:1407-18.

19. Di Filippo S. Prophylaxis of infective endocarditis in patients with congenital heart disease in the context of recent modified guidelines. Arch Cardiovasc Dis. 2012;105:454-60.

\section{EDITORIAL COMMENTARY}

\section{Endocarditis and the transcatheter pulmonary valve}

Richard A. Jonas, MD

See related article on pages 2253-9.

From the Division of Cardiovascular Surgery, Children's National Medical Center, Washington, DC.

Disclosures: Author has nothing to disclose with regard to commercial support.

Received for publication Aug 20,2014; accepted for publication Aug 20, 2014; available ahead of print Sept 27, 2014.

Address for reprints: Richard A. Jonas, MD, Division of Cardiovascular Surgery, Children's National Medical Center, 111 Michigan Ave NW, Washington, DC 20010 (E-mail: rjonas@cnmc.org).

J Thorac Cardiovasc Surg 2014;148:2259-60

$0022-5223 / \$ 36.00$

Copyright $\odot 2014$ by The American Association for Thoracic Surgery

http://dx.doi.org/10.1016/j.jtcvs.2014.08.053
The article in this issue of the Journal by MalekzadehMilani and colleagues ${ }^{1}$ from the pediatric cardiology department at the renowned Necker Hospital in Paris reports a disturbingly high risk for endocarditis in the Melody valve (Medtronic Inc, Minneapolis, Minn) relative to surgically implanted conduits. Surgically implanted conduits containing a bovine jugular valve (Contegra conduits; Medtronic Inc) also appear to have a higher risk of endocarditis relative to other surgical options.

This is an important article. There have been an increasing number of anecdotal reports in the literature suggesting that the Melody valve might have a higher risk for endocarditis than surgically implanted pulmonary valves. A multi-institutional report in 2013 described an important 